OPEN ACCESS

Edited by:

Fusheng Zhou,

Anhui Medical University, China

Reviewed by:

Fengyu Zhang,

Global Clinical and Translational Research Institute, United States

Changbing Shen,

China-Japan Friendship Hospital,

China

*Correspondence:

Caroline Lin Lin Chua linlin.chua@taylors.edu.my Wei Hsum Yap weihsum.yap@taylors.edu.my

Specialty section:

This article was submitted to

Epigenomics and Epigenetics,

a section of the journa

Frontiers in Genetics

Received: 02 December 2018

Accepted: 11 April 2019

Published: 03 May 2019

Citation:

Gunter NV, Yap BJM, Chua CLL and Yap WH (2019) Combining

Understanding of Immunological

Mechanisms and Genetic Variants Toward Development of Personalized

Medicine for Psoriasis Patients.

Front. Genet. 10:395

doi: 10.3389/fgene.2019.00395

\section{Combining Understanding of Immunological Mechanisms and Genetic Variants Toward Development of Personalized Medicine for Psoriasis Patients}

\author{
Natalie Vivien Gunter, Bryan Ju Min Yap, Caroline Lin Lin Chua* and Wei Hsum Yap* \\ School of Biosciences, Taylor's University, Subang Jaya, Malaysia
}

Psoriasis is multifactorial disease with complex genetic predisposition. Recent advances in genetics and genomics analyses have provided many insights into the relationship between specific genetic predisposition and the immunopathological mechanisms driving psoriasis manifestation. Novel approaches which utilize array-based genotyping technologies such as genome-wide association studies and bioinformatics tools for transcriptomics analysis have identified single nucleotide polymorphisms, genes and pathways that are associated with psoriasis. The discovery of these psoriasisassociated susceptibility loci, autoimmune targets and altered signaling pathways have provided opportunities to bridge the gap of knowledge from sequence to consequence, allowing new therapeutic strategies for the treatment of psoriasis to be developed. Here, we discuss recent advances in the field by highlighting how immune functions associated with psoriasis susceptibility loci may contribute to disease pathogenesis in different populations. Understanding the genetic variations in psoriasis and how these may influence the immunological pathways to cause disease will contribute to the efforts in developing novel and targeted personalized therapies for psoriasis patients.

Keywords: psoriasis, autoimmune disorder, susceptibility loci, genome-wide association studies (GWAS), personalized medicine

\section{INTRODUCTION}

Psoriasis is a chronic, inflammatory skin disorder involving hyperproliferation of epidermal keratinocytes and neo-angiogenesis (Griffiths, 2003; Lowes et al., 2014; Brembilla et al., 2018). This autoimmune disorder is multifactorial and inflammation is known to play a major role in its development. Immunohistochemistry studies have showed that $\mathrm{T}$ cells are predominantly found in psoriatic lesions (Griffiths, 2003). Activated Th1 and Th17 T cells (CD4 ${ }^{+} \mathrm{T}$ cells) and $\mathrm{CD} 8^{+} \mathrm{T}$ cells, as well as increased levels of cytokines such as IL-17, IL-23, TNF- $\alpha$ and IL-27, have been directly implicated in psoriasis immunopathogenesis (Luger and Loser, 2018). Interestingly, recent studies have shown that different genetic variations in psoriatic patients are associated with distinct disease phenotypes (Puig et al., 2014). Recent advances in genomics such as genome-wide association studies (GWAS) and SNP arrays have revealed more than 40 psoriasis susceptibility loci (Mahil et al., 2015). Genes at these loci encode for proteins that are involved in skin barrier function and 
immune cell signaling pathways (Puig et al., 2014). In this review, we will be discussing on the recent bioinformatics and experimental approaches which have led to successful discoveries of psoriasis-associated genes. In addition, we will also review on how these susceptibility loci are associated with dysregulated immune functions, which ultimately lead to the development of psoriasis, as summarized in Table 1. A better understanding of the immunopathogenic pathways in psoriasis hopefully can aid in development of novel personalized treatments for psoriasis patients.

\section{TOOLS FOR GENOME-WIDE ASSOCIATION STUDY OF PSORIASIS PATIENTS}

\section{Array-Based Technologies and Bioinformatics Analyses}

Recent experimental approaches in GWAS have revealed various new psoriasis susceptibility loci (Chen W. et al., 2016; Visscher et al., 2017). The use of arrays such as Immunochip, a custom Illumina high-density SNP array, has allowed discovery of over 15 psoriasis susceptibility loci (Tsoi et al., 2012). This genotyping array has also been used to fine-map previously discovered immune-related susceptibility loci (Bowes et al., 2015). In addition, microarray data from Affymetrix microarray chips that were analyzed using gene set enrichment analysis (GSEA) led to the identification of 65 key genes associated with psoriasis (Chen W. et al., 2016). GSEA is a computational method that allows the study of gene expression levels between normal and disease states, and is especially helpful in detecting small changes in individual genes (Chen W. et al., 2016). Utilization of exome chips such as Illumina Human Exome Fine Mapping BeadChip allowed identification of coding variants (Zuo et al., 2015). Exome genotyping arrays has the ability to detect rare SNPs and is suitable for large-scale GWAS (Guo et al., 2014). The use of these chips and arrays also provided more insights into the etiology of psoriasis.

Existing array-based approaches in GWAS have also been combined with meta-analyses such as genotype imputation. Genotype imputation is described as 'in silico genotyping, where computational analyses allow the evaluation of disease-associated genetic markers that have not been directly genotyped (Burdick et al., 2006; Li et al., 2009). For example, this method would allow individual genotypes to be determined by factoring in the distribution of the genotype between individuals such as in a pedigree or a specific population (Li et al., 2009). Therefore, this allows laboratory-based approaches such as genotyping using Illumina BeadChips or real-time polymerase chain reaction (RTPCR) to be supplemented with this computational method, where partial information of each gene can be combined and incorporated in the association analysis (Li et al., 2009; Aterido et al., 2016; Popa et al., 2016). Thus, the association hits first discovered through the array-based approach can be improved by subsequent association analysis on imputed variants (Wang and Chatterjee, 2017). In addition to that, imputation also increases the power of detection in genotypic variability-based GWAS (vGWAS) which studies non-additive loci and their effects on disease phenotypes (Wei et al., 2018).

It is also important to note that many single-marker GWAS only consider genes individually without assessing the combinatory effect of multiple causal variants or the biological consequences (Aterido et al., 2016). Genome-wide pathway analysis allows integration of such genetic and biological aspects to test functionally-related genes associated with a complex trait. For example, CXCR4 gene which contributes to the pathways driven by $I L 12 B$ gene was not previously associated with psoriasis susceptibility in single-marker GWAS but was being implicated as part of the central mechanisms of disease pathophysiology using genome-wide pathway analysis (Aterido et al., 2016). Thus, multi-genotype combination analysis enables a more elaborate study of psoriasis pathogenesis and inheritance patterns (Dou et al., 2017). PLINK software is used in this analysis to identify the association of psoriasis risk with genetic pathways and between genes in relation to psoriasis susceptibility (Bowes et al., 2015; Aterido et al., 2016). Besides that, a new algorithm, minimum distance-based enrichment analysis for genetic association (MEAGA), was recently developed to relate GWAS data to biological functions and pathways. Using this algorithm, overlapping of genes of enriched functions can be identified, linking functional and regulatory networks with psoriasis immunopathogenesis (Tsoi et al., 2017). In contrast to functional variants, non-coding variants, on the other hand, have been studied for their regulatory functions using HaploReg (v2) and expression quantitative trait locus (eQTL) databases (Yin et al., 2015). Another method of analysis used in association studies is conditional analysis, which is used to identify secondary association signals at a locus. This means that analysis by conditioning to the primary associated SNP allows testing for other significantly associated SNPs, which is useful for analyzing loci with multiple associated variants (Yang et al., 2012).

\section{Sequencing-Based Technologies}

Despite the ability of SNP arrays in identifying disease-associated genes, further molecular experiments usually needs to be carried out to confirm the implication of having these genes (Chen W. et al., 2016). Another suggested approach for GWAS analysis is through whole genome sequencing (WGS). Using this method, every variant can be directly identified through genotyping and allows concurrent discovery and fine mapping of causal variants (Wang and Chatterjee, 2017). A related approach is the whole exome sequencing (WES) which allows all protein-coding regions to be sequenced (Petersen et al., 2017). For example, using exome and targeted sequencing in a study on Chinese population, numerous missense singlenucleotide variants including LCE3D, ERAP1, and CARD14 were identified to be associated with the disease (Tang et al., 2014). Rarer variants in IL23R, GJB2, TARBP1, and FUT2 were also identified and suggested associations (Tang et al., 2014). These techniques are shown to be unbiased and provide data on variant frequencies in different populations (Petersen et al., 2017; Wu et al., 2017). A remarkable example was demonstrated by Zhou et al. (2016) where the entire 
TABLE 1 | Relationship between psoriasis immunological mechanisms and susceptibility loci in different populations.

\begin{tabular}{|c|c|c|c|c|c|}
\hline Classification & $\begin{array}{l}\text { Immunological } \\
\text { Mechanism/ } \\
\text { Target }\end{array}$ & $\begin{array}{l}\text { Psoriasis } \\
\text { Susceptibility } \\
\text { loci }\end{array}$ & $\begin{array}{l}\text { Associated } \\
\text { population }\end{array}$ & Relationship & References \\
\hline \multirow[t]{2}{*}{ Autoantigens } & LL-37 & HLA-C*06:02 & European, Chinese & $\begin{array}{l}\text { LL-37 binds to HLA-C*06:02. Complexes with } \\
\text { self-DNA to enhance plasmacytoid dendritic } \\
\text { cell production of IFN- } \gamma \text {. }\end{array}$ & $\begin{array}{l}\text { Lande et al., 2007, } \\
\text { 2014; Mabuchi and } \\
\text { Hirayama, } 2016\end{array}$ \\
\hline & ADAMTSL5 & $H L A-C^{*} 06: 02$ & European, Chinese & $\begin{array}{l}\text { Complexes with HLA-C*06:02 and is presented } \\
\text { to Va3S1/Vb13S1 TCR in CD8+ cytotoxic T } \\
\text { cell. Induces production of IL-17A and IFN- } \gamma \text {. }\end{array}$ & $\begin{array}{l}\text { Arakawa et al., 2015; } \\
\text { Fuentes-Duculan et al., } \\
2017\end{array}$ \\
\hline \multirow[t]{3}{*}{$\begin{array}{l}\text { Antigen } \\
\text { presentation }\end{array}$} & $\mathrm{B} 27$ & $H L A-B^{*} 27$ & European & $\begin{array}{l}\text { Misfolded or aberrant HLA-B27 molecules } \\
\text { present self-peptides to CD8 }{ }^{+} \text {T cells. } \\
\text { Accumulation in endoplasmic reticulum } \\
\text { stimulates ER stress response pathways and } \\
\text { the release of pro-inflammatory cytokines. }\end{array}$ & $\begin{array}{l}\text { Ruiz et al., 2012; } \\
\text { Colbert et al., 2014; } \\
\text { Eder et al., } 2017\end{array}$ \\
\hline & ERAP1 & $\begin{array}{l}\text { ERAP1 haplotype } \\
\text { (rs27524, rs26653, } \\
\text { rs30187, rs151823) }\end{array}$ & $\begin{array}{l}\text { European, } \\
\text { Romanian, Han } \\
\text { Chinese, Chinese } \\
\text { Uygur }\end{array}$ & $\begin{array}{l}\text { Modulates processing of } \mathrm{MHC} \text { class I molecule } \\
\text { and the binding of antigenic peptides to } \mathrm{MHC} \\
\text { molecule. }\end{array}$ & $\begin{array}{l}\text { Strange et al., 2010; } \\
\text { Sun et al., 2010; Lysell } \\
\text { et al., 2013; Tang et al., } \\
\text { 2014; Kenna et al., } \\
\text { 2015; Popa et al., } 2016\end{array}$ \\
\hline & ERAP2 & $\begin{array}{l}\text { ERAP2 haplotype } \\
\text { (rs2248374, } \\
\text { rs2910686) }\end{array}$ & $\begin{array}{l}\text { European, } \\
\text { Romanian }\end{array}$ & $\begin{array}{l}\text { Modulates processing of MHC class I molecule } \\
\text { and the binding of antigenic peptides to MHC } \\
\text { molecule. }\end{array}$ & Popa et al., 2016 \\
\hline IL-20 Signaling & IL-20 & $\begin{array}{l}\text { IL-20 HT GGA } \\
\text { haplotype }\end{array}$ & North Indian & $\begin{array}{l}\text { Upregulated IL-20 binds and induces STAT3 } \\
\text { activation in keratinocytes, leading to an } \\
\text { increase in cell proliferation and development of } \\
\text { psoriatic lesions. }\end{array}$ & $\begin{array}{l}\text { Lebre et al., 2012; Wani } \\
\text { et al., } 2018\end{array}$ \\
\hline \multirow[t]{4}{*}{$\begin{array}{l}\text { IL-17/23 } \\
\text { Signaling }\end{array}$} & $\begin{array}{l}\text { p40 subunit of } \\
\text { IL-12 and IL-23 }\end{array}$ & $\begin{array}{l}\text { IL-12B haplotype (A } \\
\text { allele of rs3212227 } \\
\text { and } \mathrm{G} \text { allele of } \\
\text { rs6887695) }\end{array}$ & $\begin{array}{l}\text { European, Danish, } \\
\text { Thai, Japanese }\end{array}$ & $\begin{array}{l}\text { Increased expression of } \mathrm{p} 40 \text { subunit causes an } \\
\text { increase of IFN- } \gamma \text { production, formation of IL-23 } \\
\text { and biological activities of IL-12. Polarizes T } \\
\text { cells to Th1 (by IL-12) and Th17 (by IL-23) } \\
\text { lymphocytes. }\end{array}$ & $\begin{array}{l}\text { Johnston et al., 2013; } \\
\text { Zhu et al., 2013; Tamari } \\
\text { et al., 2014; Zhao et al., } \\
\text { 2016; Loft et al., } 2018\end{array}$ \\
\hline & $\begin{array}{l}\text { p19 subunit of } \\
\text { IL-23 }\end{array}$ & IL-23A haplotypes & European, Chinese & $\begin{array}{l}\text { Promotes survival and expansion of Th17 } \\
\text { lymphocytes and the subsequent release of } \\
\text { IL-17, IL-22 and TNF- } \alpha \text {. Results in dysregulated } \\
\text { IL-23 signaling. }\end{array}$ & $\begin{array}{l}\text { Nair et al., 2009; } \\
\text { Bowes et al., 2011; } \\
\text { Chen G. et al., 2016; } \\
\text { Tsoi et al., } 2017\end{array}$ \\
\hline & IL-17A & TRAF3IP2 & $\begin{array}{l}\text { European, } \\
\text { Japanese }\end{array}$ & $\begin{array}{l}\text { IL-17A and IL-17F interacts with IL-17R recruits } \\
\text { TRAF3IP2, a positive signaling adaptor protein } \\
\text { required for activation of NF-кB signal } \\
\text { transduction and T-cell immune response. }\end{array}$ & $\begin{array}{l}\text { Ellinghaus et al., 2010; } \\
\text { Tamari et al., 2014; Tsoi } \\
\text { et al., 2015, } 2017\end{array}$ \\
\hline & PTTG1 & $\begin{array}{l}\text { PTTG1 haplotype } \\
\text { (rs2431697) }\end{array}$ & Han Chinese & $\begin{array}{l}\text { The transcription factor coded by PTTG1 } \\
\text { regulates proliferation and differentiation of } \\
\text { keratinocyte. Overexpression of the gene } \\
\text { results in hyperproliferation and impaired } \\
\text { keratinocyte differentiation, as well as } \\
\text { overproduction of TNF- } \alpha \text {. }\end{array}$ & $\begin{array}{l}\text { Sun et al., 2010; } \\
\text { Ishitsuka et al., } 2013\end{array}$ \\
\hline \multirow[t]{2}{*}{$\begin{array}{l}\mathrm{NF}-\kappa \mathrm{B} \\
\text { Signaling }\end{array}$} & ІкB-zeta & $N F K B I Z$ & European & $\begin{array}{l}\text { Transcriptional regulator of NF-кB which binds } \\
\text { to the p50 subunit of NF-кB. Also required for } \\
\text { IL-17 dependent signaling. Defective NFKBIZ } \\
\text { also affects development of Th17 lymphocytes. }\end{array}$ & Tsoi et al., 2015 \\
\hline & $\mathrm{ABIN}-1$ & $\begin{array}{l}\text { TNIP1 haplotype } \\
\text { (rs2233278) }\end{array}$ & $\begin{array}{l}\text { European, } \\
\text { Japanese, Chinese }\end{array}$ & 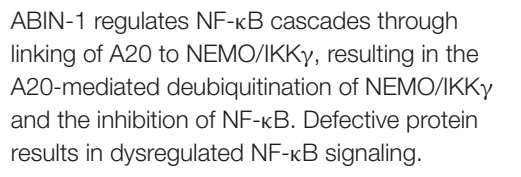 & $\begin{array}{l}\text { Bowes et al., 2011; } \\
\text { Callahan et al., 2013; } \\
\text { Tamari et al., 2014; Tsoi } \\
\text { et al., } 2017\end{array}$ \\
\hline Skin Barrier & $\begin{array}{l}\text { LCE3C and } \\
\text { LCE3B proteins }\end{array}$ & LCE3C_LCE3B-del & $\begin{array}{l}\text { Chinese, } \\
\text { Mongolian, } \\
\text { European }\end{array}$ & $\begin{array}{l}\text { Absence of LCE proteins involved in repair of } \\
\text { skin barrier injury leads to abnormal } \\
\text { keratinocyte proliferation and differentiation, } \\
\text { forming an imperfect epidermal barrier. }\end{array}$ & $\begin{array}{l}\text { de Cid et al., 2009; } \\
\text { Hüffmeier et al., 2009; } \\
\text { Zhang et al., 2009; } \\
\text { Riveira-Munoz et al., } \\
\text { 2011; Xu et al., 2011 }\end{array}$ \\
\hline
\end{tabular}

(Continued) 
TABLE 1 | Continued

\begin{tabular}{|c|c|c|c|c|c|}
\hline Classification & $\begin{array}{l}\text { Immunological } \\
\text { Mechanism/ } \\
\text { Target }\end{array}$ & $\begin{array}{l}\text { Psoriasis } \\
\text { Susceptibility } \\
\text { loci }\end{array}$ & $\begin{array}{l}\text { Associated } \\
\text { population }\end{array}$ & Relationship & References \\
\hline & LCE3D protein & $\begin{array}{l}\text { LCE3D haplotype } \\
\text { (rs512208, } \\
\text { rs4112788, } \\
\text { rs4085613) }\end{array}$ & $\begin{array}{l}\text { Han Chinese, } \\
\text { Mongolian }\end{array}$ & $\begin{array}{l}\text { Higher expression of } \angle C E 3 D \text { results in abnormal } \\
\text { formation of cornified envelope and } \\
\text { dysregulation of terminal epidermal } \\
\text { differentiation. }\end{array}$ & $\begin{array}{l}\text { Jackson et al., 2005; } \\
\text { Zhang et al., 2009; } \\
\text { Bergboer et al., 2011; } \\
\text { Tang et al., 2014; Sun } \\
\text { et al., } 2018\end{array}$ \\
\hline \multirow[t]{2}{*}{ Miscellaneous } & AIM2 & $\begin{array}{l}\text { AlM2 haplotype } \\
\text { (rs2276405) }\end{array}$ & Han Chinese & $\begin{array}{l}\text { AIM2 binds cytosolic dsDNA, forming an } \\
\text { inflammasome and activates caspase- } 1 \text { and } \\
\text { subsequently IL-1 } 1 \beta \text { in keratinocytes. }\end{array}$ & $\begin{array}{l}\text { Dombrowski et al., } \\
\text { 2011; Zuo et al., } 2015\end{array}$ \\
\hline & MGAT5 & MGAT5 haplotype & European, Spanish & $\begin{array}{l}\text { MGAT5 is required for } \mathrm{N} \text {-glycosylation of } \\
\text { asparagine residues in HLA molecules. } \\
\text { Deficiency of MGAT5 enzyme and its activity } \\
\text { reduces threshold for T cell activation, } \\
\text { increases risk of losing immune tolerance and } \\
\text { promotes triggering of autoimmune diseases. }\end{array}$ & $\begin{array}{l}\text { Demetriou et al., 2001; } \\
\text { Aterido et al., } 2016\end{array}$ \\
\hline
\end{tabular}

MHC region in the Han Chinese population was sequenced, allowing the construction of a Han-MHC reference panel which provides a summary of polymorphisms including SNPs and indels in the region. Besides discovering several new psoriasis susceptibility loci within the MHC region, development of this population-specific reference panel allowed comparison with other populations whereby a significant difference in HLA allele frequencies was discovered between Han Chinese and European populations (Zhou et al., 2016). Large-scale sequencing approaches however have not been utilized in GWAS as it is cost-ineffective and requires an extremely large sample size for discovery as opposed to array-based approaches (Petersen et al., 2017; Wang and Chatterjee, 2017).

\section{GENETIC VARIANTS AND THEIR ASSOCIATION WITH IMMUNO-PATHOLOGICAL MECHANISMS IN PSORIASIS}

\section{Autoantigens and Antigen Presentation Psoriasis Pathogenesis}

The presence of autoantigens in psoriasis patients is a wellknown factor that contributes to disease pathogenesis. Psoriasis patients may overexpress certain self-antigens which can be taken up by antigen presenting cells (APCs). Following this, the APCs may present the self-antigens on their MHC molecules and subsequently activate $\mathrm{T}$ cells via $\mathrm{T}$ cell receptors, triggering immune activation and attack on self-tissues. A study by Lande et al. (2014) found that self-reactivity to LL-37, an antimicrobial peptide, was found in two-thirds of patients with moderate-tosevere plaque psoriasis. LL-37 is produced by multiple cell types in the skin, such as keratinocytes and APCs, as a response to skin injury or bacterial layer. LL-37 then complexes with extracellular nucleic acids released during inflammation to activate myeloid dendritic cells (mDC) and plasmacytoid dendritic cells (pDC). These activated APCs release IL-23, which in turn stimulates Th17 T cells to produce IL-17A (Lande et al., 2014; Kim and Krueger, 2015; Hawkes et al., 2017b).

\section{Susceptibility Loci in Psoriasis}

In psoriasis patients, sustained stimulation of the IL-23-producing APCs by the abundance of LL-37-nucleic acid complexes contributes to the development of psoriatic inflammation. A few cohort studies of psoriatic patients from European and Chinese lineages have revealed that psoriasis and psoriatic arthritis patients have the human leukocyte antigen (HLA)-class I allele HLA$C^{*}$ 06:02 susceptibility locus, which is linked to the presentation of LL-37 autoantigen (Lande et al., 2007, 2014; Mabuchi and Hirayama, 2016; Fuentes-Duculan et al., 2017). LL-37 peptide can bind to HLA-Cw6* 02 to form a complex, which is presented by dendritic cells to $\mathrm{CD} 4^{+}$and $\mathrm{CD} 8^{+} \mathrm{T}$ cells. The specific recognition of the LL-37-HLA-Cw6*02 complex induces proliferation of these reactive $\mathrm{T}$ cells, which is not seen in stimulation by other antimicrobial peptides. The proliferation, along with production of IL-17 and IL-22, correlates with PASI, where 15 out of 20 (75\%) of patients PASI > 10 responded to LL-37 (Lande et al., 2014). ADAMTSL5, on the other hand, is a protein of the ADAMTS superfamily of metalloproteases that is proposed to play a role in microfibril formation and extracellular matrix regulation. This autoantigen has been associated with the melanocyte-derived model of psoriasis immunopathogenesis (Hawkes et al., 2017b). In psoriasis patients, their melanocytes were shown to express increased levels of ADAMTSL5 (Arakawa et al., 2015). These autoantigens are then presented by the melanocytes on their MHC class II molecules to epidermal $\mathrm{CD} 8^{+} \mathrm{T}$ cells, which are activated to release IL-17A. IL-17A may subsequently induce the production of chemokines such as CXCL1, which promotes melanocyte growth and therefore, ADAMTSL5 expansion. Recent findings also showed that ADAMTSL5 can be overexpressed in keratinocytes, thus melanocytes may not be the only autoimmune targets in psoriasis (Fuentes-Duculan et al., 2017; Hawkes et al., 2017a). Similarly, psoriasis patients with $H L A-C^{*} 06: 02$ susceptibility locus can also present ADAMTSL5 peptide as an autoantigen. The 
peptides are presented by $H L A-C^{*} 06: 02$-positive melanocytes to $\mathrm{CD}^{+} \mathrm{T}$ cells via $\mathrm{V} \alpha 3 \mathrm{~S} 1 / \mathrm{V} \beta 13 \mathrm{~S} 1 \mathrm{~T}$ cell receptor (TCR), activating production of IL-17 and IFN- $\gamma$ (Arakawa et al., 2015; Bonifacio et al., 2016; Fuentes-Duculan et al., 2017).

Another psoriasis susceptibility locus, $H L A-B^{*} 27$, encoding the MHC class I HLA-B27 molecule, was strongly associated with psoriatic arthritis in European populations and is suggested to be the strongest genetic marker for this disease (Ruiz et al., 2012; Eder et al., 2017). Several mechanisms linking this susceptibility locus to psoriatic arthritis development have been proposed. One mechanism is the ability of $\mathrm{B}^{*} 27$ to present arthritogenic peptide to $\mathrm{CD}^{+} \mathrm{T}$ cells. Another suggested mechanism is the accumulation of $\mathrm{B}^{*} 27$ heavy chain within the endoplasmic reticulum (ER), which subsequently promotes the release of pro-inflammatory cytokines (Colbert et al., 2014; Queiro et al., 2015; Bowes et al., 2017). In addition to MHC class I genes, endoplasmic reticulum aminopeptidase (ERAP1 and ERAP2) gene variations have been associated with psoriatic arthritis in the Romanian population (Popa et al., 2016). These aminopeptidases are found within the ER and function to cleave proteins into smaller peptides before they are presented on MHC class I molecules. Interestingly, it was also reported that the ERAP1 gene haplotypes (rs30187) are only associated with psoriatic arthritis in patients with the $H L A-B^{*} 27$ susceptibility locus, while ERAP1 haplotypes (rs27524, rs26653, and rs30187) also affects psoriasis susceptibility, but only in individuals with the HLA-C risk allele (Strange et al., 2010; Lysell et al., 2013; Kenna et al., 2015; Popa et al., 2016). Besides that, another ERAP1 haplotype (rs151823) has been identified, demonstrating similar association with the $H L A-C$ and type 1 psoriasis in Chinese populations (Sun et al., 2010; Tang et al., 2014). In contrast, ERAP2 gene haplotypes (rs2248374, rs2910686) are associated with disease in patients without the $H L A-B^{*} 27$ susceptibility locus (Popa et al., 2016).

\section{Cytokine Signaling Pathways Psoriasis Pathogenesis}

Therapies targeting IL-23 and/or IL-17 have shown strong efficacy in the management of psoriasis, affirming the central role of these cytokines in psoriatic inflammation (Prinz, 2017) (Figure 1). IL-23 is produced abundantly by keratinocytes and activated APCs, such as Langerhans cells and dendritic cells. Upon binding of IL-23 to its receptor (IL-23R on naïve $\mathrm{T}$ cells), the JAK2/Tyk downstream signaling pathway is activated, resulting in the phosphorylation of STAT3. In the presence of IL-23, the number of pathogenic T17 cells [Tc17 (CD8+) and Th17 (CD4+)] are increased dramatically, producing large amounts of IL-17. Other cell types, such as $\alpha \beta$ $\mathrm{T}$ cells, dermal $\gamma \delta \mathrm{T}$ cells, neutrophils and mast cell, are also capable of producing IL-17 in response to IL-23 stimulation (Blauvelt and Chiricozzi, 2018). Other cytokines produced by T17 cells, including IL-26 and IL-29, activate STAT1 to upregulate chemokines and promote recruitment of Th1 cells (Chan et al., 2018).

Keratinocytes, endothelial cells and cells of innate immunity are targets of IL-17. IL-17 can upregulate inflammatory gene expression and activate psoriasis-associated genes in epidermal keratinocytes upon binding to the IL-17R family of receptors (Amatya et al., 2017). IL-17 can also act synergistically with TNF- $\alpha$ to further upregulate these genes (Blauvelt and Chiricozzi, 2018; Chan et al., 2018). The IL-17 family of interleukins consist of IL-17A, B, C, D, E, and F. In psoriasis, IL-17A is known as the principal effector molecule that triggers inflammation, with the closely related IL-17F playing a similarly significant role. IL-17 can directly act on keratinocytes, inducing the production of IL-19 and IL-22 that promote hyperproliferation and dysregulated differentiation of epidermal keratinocytes (Chan et al., 2018). Increased levels of IL-17 can significantly upregulate the production of antimicrobial peptides in keratinocytes, IL-6, and ICAM-1 in endothelial cells to promote inflammation, and pro-inflammatory cytokines such as IL-6 in APCs (Blauvelt and Chiricozzi, 2018). ICAM1 is a vascular adhesion molecule expressed by endothelial cells, lymphocytes and keratinocytes, and is essential for $\mathrm{T}$ cell migration to the skin (Bressan et al., 2018). IL-6, IL-12, IL19, and IL-22 are associated with keratinocyte proliferation (Grossman et al., 1989; Shaker et al., 2006; Stenderup et al., 2007; Torti and Feldman, 2007). IL-17 was also shown to promote the expression of IL-23 and STAT3 in a study involving reconstructed human epidermal model (Chiricozzi et al., 2014). These events induce a positive feedback mechanism to further increases the production of both IL-23 and IL-17, creating a cycle that amplifies the inflammation and accelerates the development of psoriasis.

Another cytokine, IL-12, was found to be highly expressed in psoriatic lesions. IL-12 is a pro-Th1 heterodimeric cytokine composed of covalently-linked p40 and p35 subunits (Shaker et al., 2006). The p40 subunit of IL-12 and IL-23 is thought to be the main regulator in psoriasis and psoriatic arthritis, being associated with the formation of these interleukins and polarization of Th1 and Th17 lymphocytes respectively (Johnston et al., 2013; Zhao et al., 2016). However, IL-12 only marginally induced production of IL-17 by Th17 (Aggarwal et al., 2003). The production of IL- 12 by $\mathrm{CD}^{+}{ }^{+} \mathrm{Th} 1$ and $\mathrm{CD}^{+}$cytotoxic $\mathrm{T}$ cells along with IFN- $\gamma$ and TNF- $\alpha$ in a pattern known as the type I cytokine pattern contributes to pathogenesis of psoriasis. IL-12 stimulates $\mathrm{T}$ cells to produce IFN- $\gamma$, which induces keratinocytes to express ICAM-1 and HLA-DR. This facilitates epidermal infiltration of $\mathrm{T}$ cells, which subsequently activates keratinocytes, leading to their proliferation and development of plaque psoriasis (Shaker et al., 2006; Torti and Feldman, 2007). IL-20, a pro-inflammatory cytokine that is associated with angiogenesis and chemotaxis of leukocytes, has also been found at increased levels in psoriatic lesions. It is expressed by epidermal keratinocytes together with the IL-20 receptor (IL-20R), which suggests an autocrine signaling mechanism may be in place to maintain the inflammation in psoriasis. A previous study demonstrated that blocking IL-20 signaling in immunocompromised mice that were grafted with psoriatic plaques was able to inhibit the development of disease, proving its role in the maintenance of psoriatic inflammation (Stenderup et al., 2009). Another cytokine, IL-19, is known to contribute to psoriasis by inducing production of antimicrobial peptides, 
IL-23p19 peptides and Th17-attracting chemokines. IL-19 is produced by keratinocytes in response to IL-17, showing a feedforward loop that increases IL-17 by recruitment of Th17 cells (Witte et al., 2014).

Previous studies have identified mutations in a gene known as caspase recruitment domain family member 14 (CARD14) gene as a mediator in the immunopathogenesis of psoriasis. The gene is expressed mainly in epidermal keratinocytes and encodes for the CARD14 protein, also known as CARMA2. CARD14/CARMA2 is a scaffold protein that can activate NF- $\kappa$ B, a transcription factor that regulates multiple genes including those responsible for the production of pro-inflammatory cytokines implicated in the pathogenesis of psoriasis. A study reported that CARMA2 mutation which involves the deletion of glutamic acid at position 138 (CARMA2 $\Delta 138$ ) resulted in spontaneous development of psoriasis in $\mathrm{C} 67 \mathrm{BL} / 6 \mathrm{~J}$ mice (Mellett et al., 2018). A single copy of the gain-of-function mutation is sufficient to cause pathology. In addition, IL-23 and imiquimod treatments to induce psoriasis were shown to be unsuccessful in CARD14/CARMA2-deficient mice (Tanaka et al., 2017).

Few studies have sought to better understand the underlying mechanisms linking mutations in CARD14 gene to psoriasis development. Gain-of-function genetic mutations (CARD14 ${ }^{\mathrm{E} 138 \mathrm{~A}}$ and $C A R D 14^{\mathrm{G} 117 \mathrm{~S}}$ ) were reported to cause constitutive activation of CARD14 signaling, by promoting their interaction with BCL10 and MALT1 proteins
(Howes et al., 2016). The resulting complex is known as the CARMA-BCL10-MALT1 (CBM) complex, which can trigger NF-кB-activation, ultimately leading to cytokine production and epidermal keratinocytosis (Wang et al., 2018; Zotti et al., 2018). Mice with CARD14 genetic mutations (CARD14 ${ }^{\mathrm{E} 138 \mathrm{~A} /+}$ and $C A R D 14^{\mathrm{DQ} 136 /+}$ ) were shown to spontaneously develop psoriasis-like disease due to hyper-activation of NF- $\mathrm{B}$ and enhanced activation of IL-17A signaling in keratinocytes (Wang et al., 2018).

\section{Susceptibility Loci in Psoriasis}

Several psoriasis susceptibility loci have been associated with cytokine signaling pathways such as IL-20, IL-17/23 and NF$\kappa \mathrm{B}$ signaling pathways. Recent studies reported $I L-20$ HT GGA haplotype as the susceptibility loci for both psoriasis and psoriatic arthritis in North Indian population, where patients with this haplotype had increased IL-20 levels (Lebre et al., 2012; Wani et al., 2018). The $I L-12 B$ risk haplotype (A allele of rs3212227 and $G$ allele of rs6887695) has been identified in European, Danish, and Asian populations, specifically the Thai and Japanese populations (Johnston et al., 2013; Zhu et al., 2013; Guo et al., 2014; Tamari et al., 2014; Loft et al., 2018). Meanwhile, several SNPs in the IL23A gene which code for the p19 subunit of IL-23 identified in European and Chinese populations have been associated with psoriasis susceptibility and immunopathogenesis via IL-23 signaling (Nair et al., 2009; Bowes et al., 2011; Li et al., 2016; Tsoi et al., 2017).

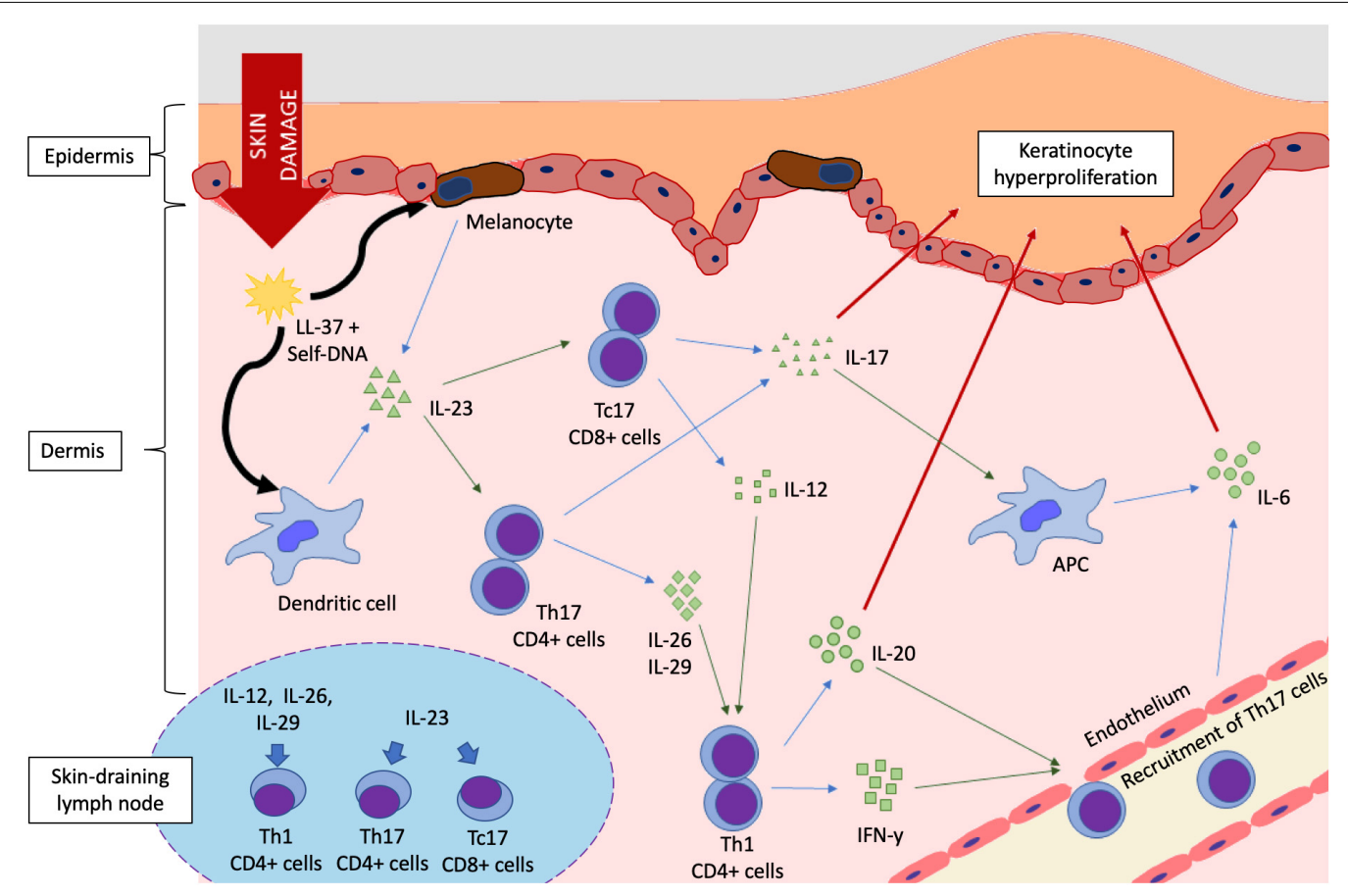

FIGURE 1 | Cytokine signaling pathways in the pathogenesis of psoriasis. Damage to the epidermal lining triggers release of antimicrobial peptides (AMP) such as LL-37, which complexes with self-DNA released from cellular membrane rupture. DNA-LL-37 complexes are autoantigens of psoriasis, which are taken up by melanocytes and dendritic cells, resulting in IL-23 production. The IL-23/IL-17 axis is activated in a feedforward loop that favors keratinocyte proliferation, eventually forming a psoriatic plaque. Schematic of lymph node (bottom left) shows the polarization of naïve T cells into Th1, Th17, and Tc17 cells by cytokine stimulation. (Key: Black arrows, uptake; Blue arrows, cytokine production; Green arrows, stimulation or activation; Red arrows, effect on epidermal keratinocytes). 
Another susceptibility locus, though with lower frequency, was identified in the IL23R gene with haplotypes rs11209026 and rs7530511 associated with European populations, and haplotype rs3762318 for Chinese populations (Tang et al., 2014). In addition, TRAF3IP2 has been identified as a susceptibility locus in European and Japanese populations for both psoriasis and psoriatic arthritis (Ellinghaus et al., 2010; Tamari et al., 2014; Tsoi et al., 2015, 2017). TRAF3IP2 encodes for an adaptor protein that is involved in IL-17 and NF$\kappa \mathrm{B}$ signaling, where binding of IL-17A and IL-17F to IL-17R leads to TRAF3IP2 recruitment, and subsequently activates NF- $\kappa \mathrm{B}$ pathway and inflammatory response (Ellinghaus et al., 2010). Another psoriasis susceptibility locus, NFKBIZ, has been identified in European populations (Tsoi et al., 2015). The gene encodes for transcriptional regulator IкB-zeta, which plays an important role in the regulation of IL-17 signaling and development of Th17 cells (Tsoi et al., 2015). Other loci involved in modulation of NF- $\mathrm{B}$ pathway in psoriasis and psoriatic arthritis includes the susceptibility loci TNIP1 gene haplotype (rs2233278), which was identified in Japanese, European, and Chinese populations (Bowes et al., 2011; Callahan et al., 2013; Tamari et al., 2014; Tsoi et al., 2017). The A20-binding protein, ABIN-1 coded by TNIP1 controls and restricts several NF- $\mathrm{BB}$ cascades through interaction with A20 to NEMO/IKK $\gamma$ (Callahan et al., 2013; Tamari et al., 2014). Besides that, CARD14 gene has also been discovered to be a susceptibility locus with the common risk haplotype rs1165075 identified in European, Spanish, and Chinese populations (Tsoi et al., 2012; González-Lara et al., 2013; Tang et al., 2014). Mutations in this gene result in a gain-of-function, causing constitutive activation of the NF- $\kappa \mathrm{B}$ pathway and as a result increases the production of pro-inflammatory cytokines (Tsoi et al., 2012; González-Lara et al., 2013).

A stop-gained variant at psoriasis susceptibility locus AIM2 (rs2276405) which codes for a cytosolic doublestranded DNA receptor has been identified in Han Chinese population (Zuo et al., 2015). Increased cytosolic DNA and AIM2 expression in keratinocytes results in the formation of inflammasomes, which trigger caspase-1 activation and subsequent pro-inflammatory IL-1 $\beta$ release (Dombrowski et al., 2011; Zuo et al., 2015). Interestingly, while LL-37 serves as an autoantigen in psoriasis immunopathogenesis, studies suggest that it can also inhibit AIM2-mediated inflammasome formation (Dombrowski et al., 2011). Meanwhile, MGAT5 gene was recently shown to be associated with psoriasis susceptibility in Spanish and European populations (Aterido et al., 2016). MGAT5 enzyme deficiency reduces the threshold required for the activation of $\mathrm{T}$ cells, thus increases the risk of losing immune tolerance and promotes susceptibility to autoimmune diseases such as psoriasis (Demetriou et al., 2001; Aterido et al., 2016).

Another identified susceptibility loci PTTG1 haplotype (rs2431697) highlights population-dependent effects, whereby it was associated with psoriasis in Han Chinese populations but not in European populations (Sun et al., 2010). This gene codes for the transcription factor involved in regulating the proliferation and differentiation of keratinocytes and was found to be overexpressed in psoriasis which subsequently leads to overproduction of TNF- $\alpha$ and the resultant inflammation (Ishitsuka et al., 2013). Sun et al. (2010) also reported other psoriasis susceptibility loci such as CSMD1, GJB2, SERPINB8 and ZNF816A in Han Chinese population.

\section{Skin Barrier \\ Psoriasis Pathogenesis}

Human skin is equipped with barrier function to prevent entry and invasion of pathogens. It is composed of physical barrier, permeability barrier, and innate and adaptive barriers. The permeability barrier lies within the stratum corneum layer and is dependent on corneocytes and the lipid-rich matrix surrounding the cells (Sano, 2015). Stratum corneum is formed through terminal differentiation of epithelial keratinocytes. It is composed of various lipids and proteins, including members of the late cornified envelope (LCE) protein family (Niehues et al., 2016). The LCE gene cluster is located on chromosome 1q21, where it encodes for 18 proteins whose functions are largely unknown. It is hypothesized that the LCE genes encode for structural proteins are involved in the repair of skin barrier and play an important role in cornified epithelial differentiation (Jackson et al., 2005; Sano, 2015). In particular, LCE3B and 3C proteins are known to be crucial in promoting the recovery of the skin barrier. In the normal skin, LCE3B and 3C proteins are usually expressed at low to negligible levels, but their expression can be induced following mechanical stripping of the cornified epithelial layer (de Cid et al., 2009). However, in individuals without these genes, the epidermal barrier cannot be properly repaired due to abnormal keratinocyte differentiation and proliferation (Zhang et al., 2009; Xu et al., 2011). The compromised skin barrier enables easier penetration of exogenous agents, which may then activate host immune responses in the skin and promote psoriatic development (de Cid et al., 2009; Coto et al., 2011). This mechanism of immune activation leading to psoriasis is especially common in patients who are $H L A-C w 6$ positive (de Cid et al., 2009).

\section{Susceptibility Loci in Psoriasis}

In the recent years, discovery of a biallelic $L C E 3 C \_L C E 3 B$ del copy number variant has been identified and was linked to psoriasis susceptibility (de Cid et al., 2009; Riveira-Munoz et al., 2011). This 32.2-kb gene deletion removes functioning genes of $L C E 3 C$ and $L C E 3 B$ in the LCE cluster on chromosome 1q21.3 (Riveira-Munoz et al., 2011). In addition to gene deletion, various studies have characterized several associations between this LCE susceptibility loci and other risk factors in different populations. For example, epistatic effect with HLA-Cw6 allele was reported in Dutch and US Michigan populations (de Cid et al., 2009; Riveira-Munoz et al., 2011). This association with the HLA-Cw6 status, however, was not marked in other studied populations including Chinese, Mongolian and other European ancestries (de Cid et al., 2009; Hüffmeier et al., 2010; Riveira-Munoz et al., 2011; Xu et al., 2011). It was hypothesized that these distinct findings in different populations may be attributed to variations in genetic 
backgrounds, as well as environmental factors (Xu et al., 2011). A few studies have also investigated if the LCE3C_LCE3B-del gene loci are specifically associated only with the development of skin-related psoriasis vulgaris, or with psoriatic arthritis as well. Two contrasting findings were obtained in different populations; there was no association between this gene loci and psoriatic arthritis in the German population (Hüffmeier et al., 2009), while other studies done on the British population found an association between this loci and psoriatic arthritis (Bowes et al., 2010; Zhang et al., 2016).

Besides that, another susceptibility locus was identified within the LCE cluster, specifically haplotypes of LCE3D gene (rs512208, rs4112788, rs4085613) in Han Chinese and Mongolian populations (Zhang et al., 2009; Tang et al., 2014; Sun et al., 2018). The late envelope protein 16 which is coded by this gene is involved in the formation of the cornified envelope as well as the regulation of terminal epidermal differentiation (Jackson et al., 2005). Studies reveal a higher expression of $L C E 3 D$ in psoriatic samples and is thus hypothesized to contribute to the formation of psoriatic lesions (Bergboer et al., 2011).

\section{GENETIC VARIANTS AND PERSONALIZED MEDICINE FOR PSORIASIS}

Identifying the causal alleles within the refined association signals will help to guide the development of targeted treatments. Pathogenic insights obtained from large-scale GWAS studies have identified IL-23 and IL-17 as key disease drivers that can be targeted by various classes of therapeutics. It informed the development of ustekinumab, a drug which targets the p40 subunit shared by IL-12 and IL-23 (SNPs in IL12B which encodes p40 are associated with psoriasis susceptibility). The p40 unit shared by IL-12 and IL-23 is an attractive therapeutic target as it influences two important effector cytokines, IFN $\gamma$ and IL-17. Meanwhile, the development of IL-23A and IL-17 inhibitors were informed by GWAS analysis which led to the development of IL-17 blockers such as Secukinumab (Cosentyx), ixekizumab (Taltz) and broadalumab (Kyntheum) and IL-23 inhibitors including Guselkumab (Tremfya), and tildrakizumab. There are no risk alleles in $I L 17 A$, but psoriasis-associated SNPs have been identified in TRAF3IP2, which encodes an IL-17 receptor adaptor while SNPs in IL23A, which encodes p19, are associated with psoriasis susceptibility.

The current treatments for psoriasis however are limited by inter-individual variation in efficacy. Advances in GWAS allow researchers to make further associations between genetic variants of genomic loci and their corresponding phenotypic differences, which assist in risk prediction for targeted prevention or intervention strategies and provide discovery pipeline for new drug. In clinical trials, PASI-75 was achieved in more than $60 \%$ of ustekinumab-treated psoriasis patients at 12 weeks. Interestingly, current associations between the $H L A-C w^{*} 06$ genotype and response to ustekinumab have shown conflicting findings. While a retrospective study of 255 patients have shown $71.7 \%$ of $C w^{*} 06$-positive patients reached PASI 50 at week 4 compared with $35.2 \%$ of those who were $\mathrm{Cw}^{*} 06$ negative (Talamonti et al., 2017), a differential response was also reported in a study of 332 patients in which $62 \%$ of $C w^{*} 06$-positive patients vs. $48 \%$ of $C w^{*} 06$ - negative patients reached PASI 50 after 4 weeks of therapy (Li et al., 2016). In contrast, some even found no association of $\mathrm{Cw}^{*} 06$ genotype with response to ustekinumab treatment in 69 patients with psoriasis treated with ustekinumab (Prieto-Perez et al., 2017). These pharmacogenetic studies have identified the effects of variants in specific genes that are associated with clinical response to treatments, which can be used to inform patient care and reduce drug-related costs.

Collaborative efforts from various stakeholders may be able to assist in detailed assessment of GWAS data. Recently, the Psoriasis Stratification to Optimize Relevant Therapy (PSORT) consortium was formed to improve understanding of the determinants of responses to biologic therapies for psoriasis ${ }^{1}$. It uses the large-scale United Kingdom-based clinical data resource called British Association of Dermatologists' Biologic Interventions Registry and integrates this with genetic, immune, and transcriptomic data for patients treated with biologics. Data gathered from large scale consortium studies will provide insights for personalized medicine in psoriasis patients whereby individual genetic profiles can be used to define prognosis, including the disease subtype, response to specific medications, and prediction of potential adverse drugs reactions.

\section{CONCLUSION}

Although GWAS contributed insight into the utility of the genotype biomarker to treatment selection, adequately powered prospective studies will be required before clinical application of pharmacogenomics can become a reality. Genotype and phenotype assessment should be facilitated by the availability of detailed molecular analyses and data integration. Careful assessment of prospective GWAS data is essential to integrate findings into the clinical decision-making process, and thereby optimizing the treatment of patients with psoriasis in the future.

\section{AUTHOR CONTRIBUTIONS}

BY, NG, and WY performed the project. CC provided vital guidance and insight to the work. WY and CC conceptualized the project.

\section{FUNDING}

This work was supported by the Ministry of Education (MOE) Fundamental Research Grant Scheme (FRGS/1/2015/SKK08/ TAYLOR/03/2) awarded to CC; Taylor's Research Grant Scheme Major Grant (TRGS/MFS/1/2015/SBS/013) awarded to WY.

\footnotetext{
${ }^{1}$ www.psort.org.uk
} 


\section{REFERENCES}

Aggarwal, S., Ghilardi, N., Xie, M. H., De Sauvage, F. J., and Gurney, A. L. (2003). Interleukin-23 promotes a distinct CD4 T cell activation state characterized by the production of interleukin-17. J. Biol. Chem. 278, 1910-1914.

Amatya, N., Garg, A. V., and Gaffen, S. L. (2017). IL-17 signaling: the yin and the yang. Trends Immunol. 38, 310-322. doi: 10.1016/j.it.2017.01.006

Arakawa, A., Siewert, K., Stöhr, J., Besgen, P., Kim, S.-M., Rühl, G., et al. (2015). Melanocyte antigen triggers autoimmunity in human psoriasis. J. Exp. Med. 212, 2203-2212. doi: 10.1084/jem.20151093

Aterido, A., Julià, A., Ferrándiz, C., Puig, L., Fonseca, E., Fernández-López, E., et al. (2016). Genome-wide pathway analysis identifies genetic pathways associated with psoriasis. J. Investig. Dermatol. 136, 593-602.

Bergboer, J. G. M., Tjabringa, G. S., Rodijk-olthuis, D., Jansen, P. A. M., Thuret, J., and Narita, M. (2011). Psoriasis risk genes of the late cornified envelope-3 group are distinctly expressed compared with genes of other LCE groups. Am. J. Pathol. 178, 1470-1477. doi: 10.1016/j.ajpath.2010.12.017

Blauvelt, A., and Chiricozzi, A. (2018). The immunologic role of IL-17 in psoriasis and psoriatic arthritis pathogenesis. Clin. Rev. Allergy Immunol. 55, 379-390.

Bonifacio, K. M., Kunjravia, N., Krueger, J. G., and Fuentes-Duculan, J. (2016). Cutaneous expression of A Disintegrin-like and Metalloprotease domain containing Thrombospondin type 1 motif-like 5 (ADAMTSL5) in psoriasis goes beyond melanocytes. J. Pigment. Disord. 3:244.

Bowes, J., Ashcroft, J., Dand, N., Jalali-Najafabadi, F., Bellou, E., Ho, P., et al. (2017). Cross-phenotype association mapping of the MHC identifies genetic variants that differentiate psoriatic arthritis from psoriasis. Ann. Rheum. Dis. 76, 1774-1779. doi: 10.1136/annrheumdis-2017-211414

Bowes, J., Budu-Aggrey, A., Huffmeier, U., Uebe, S., Steel, K., Hebert, H. L., et al. (2015). Dense genotyping of immune-related susceptibility loci reveals new insights into the genetics of psoriatic arthritis. Nat. Commun. 6:6046. doi: $10.1038 /$ ncomms7046

Bowes, J., Flynn, E., Ho, P., Aly, B., Morgan, A. W., Marzo-Ortega, H., et al. (2010). Variants in linkage disequilibrium with the late cornified envelope gene cluster deletion are associated with susceptibility to psoriatic arthritis. Ann. Rheum. Dis. 69, 2199-2203. doi: 10.1136/ard.2010.130575

Bowes, J., Orozco, G., Flynn, E., Ho, P., Brier, R., Marzo-Ortega, H., et al. (2011). Confirmation of TNIP1 and IL23A as susceptibility loci for psoriatic arthritis. Ann. Rheum. Dis. 70, 1641-1644. doi: 10.1136/ard.2011.150102

Brembilla, N. C., Senra, L., and Boehncke, W. H. (2018). The IL-17 family of cytokines in psoriasis: IL-17A and beyond. Front. Immunol. 9:1682. doi: 10. 3389/fimmu.2018.01682

Bressan, A. L., Picciani, B. L. S., Azulay-Abulafia, L., Fausto-Silva, A. K., Almeida, P. N., Cunha, K. S. G., et al. (2018). Evaluation of ICAM-1 expression and vascular changes in the skin of patients with plaque, pustular, and erythrodermic psoriasis. Int. J. Dermatol. 57, 209-216. doi: 10.1111/ijd.13883

Burdick, J. T., Chen, W., Abecasis, G. R., and Cheung, V. G. (2006). In silico method for inferring genotypes in pedigrees. Nat. Genet. 38, 1002-1004.

Callahan, J. A., Hammer, G. E., Agelides, A., Duong, B. H., Oshima, S., North, J., et al. (2013). Cutting edge: ABIN-1 protects against psoriasis by restricting MyD88 signals in dendritic cells. J. Immunol. 191, 535-539. doi: 10.4049/ jimmunol.1203335

Chan, T. C., Hawkes, J. E., and Krueger, J. G. (2018). Interleukin 23 in the skin: role in psoriasis pathogenesis and selective interleukin 23 blockade as treatment. Ther. Adv. Chronic Dis. 9, 111-119. doi: 10.1177/2040622318759282

Chen, G., Li, C., and Chen, K. (2016). Fructooligosaccharides: a review on their mechanisms of action and effects. Stud. Nat. Prod. Chem. 48, 209-229.

Chen, W., Xie, K., Liu, X., and Chen, H. (2016). Identification of key pathways and genes in psoriasis via gene microarray analysis. Mol. Med. Rep. 13, 2327-2337. doi: $10.3892 / \mathrm{mmr} .2016 .4790$

Chiricozzi, A., Nograles, K. E., Johnson-Huang, L. M., Fuentes-Duculan, J., Cardinale, I., Bonifacio, K. M., et al. (2014). IL-17 induces an expanded range of downstream genes in reconstituted human epidermis model. PLoS One 9:e90284. doi: 10.1371/journal.pone.0090284

Colbert, R. A., Tran, T. M., and Layh-Schmitt, G. (2014). HLA-B27 misfolding and ankylosing spondylitis. Mol. Immunol. 57, 44-51. doi: 10.1016/j.molimm.2013. 07.013
Coto, E., Santos-Juanes, J., Coto-Segura, P., and Alvarez, V. (2011). New psoriasis susceptibility genes: momentum for skin-barrier disruption. J. Investig. Dermatol. 131, 1003-1005. doi: 10.1038/jid.2011.14

de Cid, R., Riveira-munoz, E., Zeeuwen, P. L., Robarge, J., Liao, W., Dannhauser, E. N., et al. (2009). Deletion of the late cornified envelope LCE3B and LCE3C genes as a susceptibility factor for psoriasis. Nat. Genet. 41, 211-215. doi: 10. 1038/ng.313

Demetriou, M., Granovsky, M., Quaggin, S., and Dennis, J. W. (2001). Negative regulation of T-cell activation and autoimmunity by Mgat5 N-glycosylation. Nature 409, 733-739.

Dombrowski, Y., Peric, M., Koglin, S., Kammerbauer, C., Anz, D., Simanski, M., et al. (2011). Cytosolic DNA triggers inflammasome activation in keratinocytes in psoriatic lesions. Sci. Transl. Med. 3:82ra38. doi: 10.1126/scitranslmed. 3002001

Dou, J., Guo, H., Cheng, F., Huang, H., Fu, L., Li, L., et al. (2017). Genotype combination contributes to psoriasis: an exhaustive algorithm perspective. PLoS One 12:e0186067. doi: 10.1371/journal.pone.0186067

Eder, L., Abji, F., Rosen, C. F., Chandran, V., and Gladman, D. D. (2017). The association between obesity and clinical features of psoriatic arthritis: a case-control study. J. Rheumatol. 44, 437-443.

Ellinghaus, E., Ellinghaus, D., Stuart, P. E., Nair, R. P., Debrus, S., Raelson, J. V., et al. (2010). Genome-wide association study identifies a psoriasis susceptibility locus at TRAF3IP2. Nat. Genet. 42, 991-995. doi: 10.1038/ng.689

Fuentes-Duculan, J., Bonifacio, K. M., Kunjravia, N., Hawkes, J. E., Cueto, I., Li, X., et al. (2017). Autoantigens ADAMTSL5 and LL37 are significantly upregulated in active Psoriasis and localized with keratinocytes, dendritic cells and other leukocytes. Exp. Dermatol. 26, 1075-1082. doi: 10.1111/exd.13378

González-Lara, L., Coto-Segura, P., Penedo, A., Eiris, N., Díaz, M., Santos-Juanes, J., et al. (2013). SNP rs11652075 in the CARD14 gene as a risk factor for psoriasis (PSORS2) in a Spanish cohort. DNA Cell Biol. 32, 601-604. doi: 10.1089/dna. 2013.2109

Griffiths, C. E. M. (2003). The immunological basis of psoriasis. J. Eur. Acad. Dermatol. Venereol. 17(Suppl. 2), 1-5.

Grossman, R. M., Krueger, J., Yourish, D., Granelli-Piperno, A., Murphy, D. P., May, L. T., et al. (1989). Interleukin 6 is expressed in high levels in psoriatic skin and stimulates proliferation of cultured human keratinocytes. Proc. Natl. Acad. Sci. U. S.A. 86, 6367-6371.

Guo, Y., He, J., Zhao, S., Wu, H., Zhong, X., Sheng, Q., et al. (2014). Illumina human exome genotyping array clustering and quality control. Nat. Protoc. 9, 2643-2662. doi: 10.1038/nprot.2014.174

Hawkes, J. E., Chan, T. C., and Krueger, J. G. (2017a). Psoriasis pathogenesis and the development of novel targeted immune therapies. J. Allergy Clin. Immunol. 140, 645-653.

Hawkes, J. E., Gonzalez, J. A., and Krueger, J. G. (2017b). Autoimmunity in psoriasis: evidence for specific autoantigens. Curr. Dermatol. Rep. 6, 104-112.

Howes, A., OSullivan, P. A., Breyer, F., Ghose, A., Cao, L., Krappmann, D., et al. (2016). Psoriasis mutations disrupt CARD14 autoinhibition promoting BCL10MALT1-dependent NF- $\mathrm{B}$ activation. Biochem. J. 473, 1759-1768. doi: 10.1042/ BCJ20160270

Hüffmeier, U., Bergboer, J. G. M., Becker, T., Armour, J. A., Traupe, H., Estivill, X., et al. (2010). Replication of LCE3C-LCE3B CNV as a risk factor for psoriasis and analysis of interaction with other genetic risk factors. J. Investig. Dermatol. 130, 979-984. doi: 10.1038/jid.2009.385

Hüffmeier, U., Estivill, X., Riveira-munoz, E., Traupe, H., Wendler, J., Lohmann, J., et al. (2009). Deletion of LCE3C and LCE3B genes at PSORS4 does not contribute to susceptibility to psoriatic arthritis in German patients. Ann. Rheum. Dis. 69, 876-878. doi: 10.1136/ard.2009.108951

Ishitsuka, Y., Kawachi, Y., Maruyama, H., Taguchi, S., Fujisawa, Y., Furuta, J., et al. (2013). Pituitary tumor transforming gene 1 induces tumor necrosis factor- $\alpha$ production from keratinocytes: implication for involvement in the pathophysiology of psoriasis. J. Investig. Dermatol. 133, 2566-2575. doi: 10. 1038/jid.2013.189

Jackson, B., Tilli, C. M. L. J., Hardman, M. J., Avilion, A. A., MacLeod, M. C., Ashcroft, G. S., et al. (2005). Late cornified envelope family in differentiating epithelia - Response to calcium and ultraviolet irradiation. J. Investig. Dermatol. $124,1062-1070$.

Johnston, A., Xing, X., Swindell, W. R., Kochkodan, J., Riblett, M., Nair, R. P., et al. (2013). Susceptibility-associated genetic variation at IL12B enhances Th1 
polarization in psoriasis. Hum. Mol. Genet. 22, 1807-1815. doi: 10.1093/hmg/ ddt034

Kenna, T. J., Robinson, P. C., and Haroon, N. (2015). Endoplasmic reticulum aminopeptidases in the pathogenesis of ankylosing spondylitis. Rheumatology 54, 1549-1556.

Kim, J., and Krueger, J. G. (2015). The immunopathogenesis of psoriasis. Dermatol. Clin. 33, 13-23. doi: 10.1016/j.det.2014.09.002

Lande, R., Botti, E., Jandus, C., Dojcinovic, D., Fanelli, G., Conrad, C., et al. (2014). The antimicrobial peptide LL37 is a T-cell autoantigen in psoriasis. Nat. Commun. 5:5621. doi: 10.1038/ncomms6621

Lande, R., Gregorio, J., Facchinetti, V., Chatterjee, B., Wang, Y. H., Homey, B., et al. (2007). Plasmacytoid dendritic cells sense self-DNA coupled with antimicrobial peptide. Nature $449,564-569$.

Lebre, M. C., Jonckheere, C. L., Kraan, M. C., van Kuijk, A. W. R., Bos, J. D., de Rie, M., et al. (2012). Expression of IL-20 in synovium and lesional skin of patients with psoriatic arthritis: differential response to alefacept treatment. Arthritis Res. Ther. 14:R200. doi: 10.1186/ar4038

Li, F. F., Zhu, X. D., Yan, P., Jin, M. H., Yue, H., Zhang, Q., et al. (2016). Characterization of variations in IL23A and IL23R genes: possible roles in multiple sclerosis and other neuroinflammatory demyelinating diseases. Aging 8, 2734-2746. doi: 10.18632/aging.101058

Li, Y., Willer, C., Sanna, S., and Abecasis, G. R. (2009). Genotype imputation. Annu. Rev. Genomics Hum. Genet. 10, 387-406.

Loft, N. D., Skov, L., Rasmussen, M. K., Gniadecki, R., Dam, T. N., Brandslund, I., et al. (2018). Genetic polymorphisms associated with psoriasis and development of psoriatic arthritis in patients with psoriasis. PLoS One 13:e0192010. doi: 10.1371/journal.pone. 0192010

Lowes, M. A., Suárez-Fariñas, M., and Krueger, J. G. (2014). Immunology of psoriasis. Annu. Rev. Immunol. 32, 227-255. doi: 10.1146/annurev-immunol032713-120225

Luger, T. A., and Loser, K. (2018). Novel insights into the pathogenesis of psoriasis. Clin. Immunol. 186, 43-45.

Lysell, J., Padyukov, L., Kockum, I., Nikamo, P., and Ståhle, M. (2013). Genetic association with ERAP1 in psoriasis is confined to disease onset after puberty and not dependent on HLA-C*06. J. Investig. Dermatol. 133, 411-417. doi: $10.1038 /$ jid.2012.280

Mabuchi, T., and Hirayama, N. (2016). Binding affinity and interaction of LL-37 with HLA-C*06:02 in psoriasis. J. Investig. Dermatol. 136, 1901-1903.

Mahil, S. K., Capon, F., and Barker, J. N. (2015). Genetics of psoriasis. Dermatol. Clin. 33, 1-11. doi: 10.1016/j.det.2014.09.001

Mellett, M., Meier, B., Mohanan, D., Schairer, R., Cheng, P., Satoh, T. K., et al. (2018). CARD14 gain-of-function mutation alone is sufficient to drive IL-23/IL17 -mediated psoriasiform skin inflammation in vivo. J. Investig. Dermatol. 138, 2010-2023. doi: 10.1016/j.jid.2018.03.1525

Nair, R. P., Duffin, K. C., Helms, C., Ding, J., Stuart, P. E., Goldgar, D., et al. (2009). Genome-wide scan reveals association of psoriasis with IL-23 and NF-kB pathways. Nat. Genet. 41, 199-204. doi: 10.1038/ng.311

Niehues, H., Van Vlijmen-Willems, I. M., Bergboer, J. G., Kersten, F. F., Narita, M., Hendriks, W. J., et al. (2016). Late cornified envelope (LCE) proteins: distinct expression patterns of LCE2 and LCE3 members suggest nonredundant roles in human epidermis and other epithelia. Br. J. Dermatol. 174, 795-802. doi: $10.1111 /$ bjd.14284

Petersen, B. S., Fredrich, B., Hoeppner, M. P., Ellinghaus, D., and Franke, A. (2017). Opportunities and challenges of whole-genome and -exome sequencing. $B M C$ Genet. 18:14. doi: 10.1186/s12863-017-0479-5

Popa, O. M., Cherciu, M., Cherciu, L. I., Dutescu, M. I., Bojinca, M., Bojinca, V., et al. (2016). ERAP1 and ERAP2 gene variations influence the risk of psoriatic arthritis in Romanian population. Arch. Immunol. Ther. Exp. 64, 123-129. doi: 10.1007/s00005-016-0444-4

Prieto-Perez, R., Llamas-Velasco, M., Cabaleiro, T., Solano-Lopez, G., Marquez, B., Roman, M., et al. (2017). Pharmacogenetics of ustekinumab in patients with moderate-to-severe plaque psoriasis. Pharmacogenomics 18, 157-164. doi: 10.2217/pgs-2016-0122

Prinz, J. C. (2017). Autoimmune aspects of psoriasis: heritability and autoantigens. Autoimmun. Rev. 16, 970-979. doi: 10.1016/j.autrev.2017. 07.011

Puig, L., Julià, A., and Marsal, S. (2014). The pathogenesis and genetics of psoriasis. Actas Dermosifiliogr. 105, 535-545.
Queiro, R., Morante, I., Cabezas, I., and Acasuso, B. (2015). HLA-B27 and psoriatic disease: a modern view of an old relationship. Rheumatology 55, 221-229. doi: 10.1093/rheumatology/kev296

Riveira-Munoz, E., Su-Min, H., Escaramís, G., Stuart, P. E., Huffmeier, U., Lee, C., et al. (2011). Meta-analysis confirms the LCE3C_LCE3B deletion as a risk factor for psoriasis in several ethnic groups and finds interaction with HLA-Cw6. J. Investig. Dermatol. 131, 1105-1109. doi: 10.1038/jid.2010.350

Ruiz, D. G., de Azevedo, M. N. L., and Lupi, O. (2012). HLA-B27 frequency in a group of patients with psoriatic arthritis. An. Bras. Dermatol. 87, 847-850.

Sano, S. (2015). Psoriasis as a barrier disease. Dermatol. Sin. 33, 64-69.

Shaker, O. G., Moustafa, W., Essmat, S., Abdel-Halim, M., and El-Komy, M. (2006). The role of interleukin-12 in the pathogenesis of psoriasis. Clin. Biochem. 39, $119-125$.

Stenderup, K., Rosada, C., Worsaae, A., Clausen, J. T., and Dam, T. N. (2007). Interleukin-20 as a target in psoriasis treatment. Ann. N. Y. Acad. Sci. 1110, 368-381.

Stenderup, K., Rosada, C., Worsaae, A., Dagnaes-Hansen, F., Steiniche, T., Hasselager, E., et al. (2009). Interleukin-20 plays a critical role in maintenance and development of psoriasis in the human xenograft transplantation model. Br. J. Dermatol. 160, 284-296. doi: 10.1111/j.1365-2133.2008.08890.x

Strange, A., Capon, F., Spencer, C. C., Knight, J., Weale, M. E., Allen, M. H., et al. (2010). Genome-wide association study identifies new psoriasis susceptibility loci and an interaction between HLA-C and ERAP1. Nat. Genet. 42, 985-990. doi: 10.1038/ng.694

Sun, L., Cao, Y., He, N., Han, J., Hai, R., Arlud, S., et al. (2018). Association between LCE gene polymorphisms and psoriasis vulgaris among Mongolians from Inner Mongolia. Arch. Dermatol. Res. 310, 321-327. doi: 10.1007/s00403-018-1813-0

Sun, L. D., Cheng, H., Wang, Z. X., Zhang, A. P., Wang, P. G., Xu, J. H., et al. (2010). Association analyses identify six new psoriasis susceptibility loci in the Chinese population. Nat. Genet. 42, 1005-1009. doi: 10.1038/ng.690

Talamonti, M., Galluzzo, M., van den Reek, J. M., de Jong, E. M., Lambert, J. L. W., Malagoli, P., et al. (2017). Role of the HLA-C*06 allele in clinical response to ustekinumab: evidence from real life in a large cohort of European patients. $B r$. J. Dermatol. 177, 489-496. doi: 10.1111/bjd.15387

Tamari, M., Saeki, H., Hayashi, M., Umezawa, Y., Ito, T., Fukuchi, O., et al. (2014). An association study of 36 psoriasis susceptibility loci for psoriasis vulgaris and atopic dermatitis in a Japanese population. J. Dermatol. Sci. 76, 149-157.

Tanaka, M., Kobiyama, K., Honda, T., Uchio-Yamada, K., Natsume-Kitatani, Y., Mizuguchi, K., et al. (2017). Essential role of CARD14 in murine experimental psoriasis. J. Immunol. 200, 71-81. doi: 10.4049/jimmunol.1700995

Tang, H., Jin, X., Li, Y., Jiang, H., Tang, X., Yang, X., et al. (2014). A large-scale screen for coding variants predisposing to psoriasis. Nat. Genet. 46, 45-50. doi: 10.1038/ng.2827

Torti, D. C., and Feldman, S. R. (2007). Interleukin-12, interleukin-23, and psoriasis: current prospects. J. Am. Acad. Dermatol. 57, 1059-1068.

Tsoi, L. C., Spain, S. L., Ellinghaus, E., Stuart, P. E., Capon, F., Knight, J., et al. (2015). Enhanced meta-analysis and replication studies identify five new psoriasis susceptibility loci. Nat. Commun. 6:7001. doi: 10.1038/ncomms8001

Tsoi, L. C., Spain, S. L., Knight, J., Ellinghaus, E., Stuart, P. E., Capon, F., et al. (2012). Identification of 15 new psoriasis susceptibility loci highlights the role of innate immunity. Nat. Genet. 44, 1341-1348. doi: 10.1038/ng.2467

Tsoi, L. C., Stuart, P. E., Tian, C., Gudjonsson, J. E., Das, S., Zawistowski, M., et al. (2017). Large scale meta-analysis characterizes genetic architecture for common psoriasis associated variants. Nat. Commun. 8:15382. doi: 10.1038/ ncomms 15382

Visscher, P. M., Wray, N. R., Zhang, Q., Sklar, P., McCarthy, M. I., Brown, M. A., et al. (2017). 10 years of GWAS discovery: biology, function, and translation. Am. J. Hum. Genet. 101, 5-22. doi: 10.1016/j.ajhg.2017.06.005

Wang, M., Zhang, S., Zheng, G., Huang, J., Zhou, S., Zhao, X., et al. (2018). Gain-of-function mutation of Card14 leads to spontaneous psoriasis-like skin inflammation through enhanced keratinocyte response to IL-17A. Immunity 49, 66-79.e5. doi: 10.1016/j.immuni.2018.05.012

Wang, Z., and Chatterjee, N. (2017). Increasing mapping precision of genomewide association studies: to genotype and impute, sequence, or both? Genome Biol. $18,17-19$.

Wani, A., Ganai, B. A., Akhtar, T., Narang, T., and Kaur, R. (2018). Association of proinflammatory cytokine IL-20 gene polymorphism with psoriasis in north Indian population. Egypt. J. Med. Hum. Genet. 19, 201-205. 
Wei, W. H., Massey, J., Worthington, J., Barton, A., and Warren, R. B. (2018). Genotypic variability-based genome-wide association study identifies nonadditive loci HLA-C and IL12B for psoriasis. J. Hum. Genet. 63, 289-296. doi: 10.1038/s10038-017-0350-6

Witte, E., Kokolakis, G., Witte, K., Philipp, S., Doecke, W. D., Babel, N., et al. (2014). IL-19 is a component of the pathogenetic IL-23/IL-17 cascade in psoriasis. J. Investig. Dermatol. 134, 2757-2767. doi: 10.1038/jid.2014.308

Wu, Y., Zheng, Z., Visscher, P. M., and Yang, J. (2017). Quantifying the mapping precision of genome-wide association studies using whole-genome sequencing data. Genome Biol. 18:86. doi: 10.1186/s13059-017-1216-0

Xu, L., Li, Y., Zhang, X., Sun, H., Sun, D., Jia, X., et al. (2011). Deletion of LCE 3 C and LCE $3 \mathrm{~B}$ genes is associated with psoriasis in a northern Chinese population. Br. J. Dermatol. 165, 882-887. doi: 10.1111/j.1365-2133.2011.10485.X

Yang, J., Ferreira, T., Morris, A. P., Medland, S. E., Madden, P. A., Heath, A. C., et al. (2012). Conditional and joint multiple-SNP analysis of GWAS summary statistics identifies additional variants influencing complex traits. Nat. Genet. 44, 369-375. doi: 10.1038/ng.2213

Yin, X., Low, H. Q., Wang, L., Li, Y., Ellinghaus, E., Han, J., et al. (2015). Genome-wide meta-analysis identifies multiple novel associations and ethnic heterogeneity of psoriasis susceptibility. Nat. Commun. 6:6916. doi: 10.1038/ ncomms7916

Zhang, X., Huang, W., Yang, S., Sun, L., Zhang, F., Zhu, Q., et al. (2009). Psoriasis genome-wide association study identifies susceptibility variants within LCE gene cluster at 1q21. Nat. Genet. 41, 205-210. doi: 10.1038/ng.310

Zhang, Z., Yuan, J., Tian, Z., Xu, J., and Lu, Z. (2016). Investigation of 36 non-HLA (human leucocyte antigen) psoriasis susceptibility loci in a psoriatic arthritis cohort. Arch. Dermatol. Res. 309, 71-77. doi: 10.1007/s00403-016-1706-z
Zhao, Z., Xie, F., Zhang, X., Yang, J., Wang, R., Yang, R., et al. (2016). Update on the association between interleukin-12 p40 gene polymorphism and risk of psoriasis: a meta-analysis. Dermatol. Sin. 34, 126-130.

Zhou, F., Cao, H., Zuo, X., Zhang, T., Zhang, X., Liu, X., et al. (2016). Deep sequencing of the MHC region in the Chinese population contributes to studies of complex disease. Nat. Genet. 48, 740-746. doi: 10.1038/ ng.3576

Zhu, K. J., Zhu, C. Y., Shi, G., and Fan, Y. M. (2013). Meta-analysis of IL12B polymorphisms (rs3212227, rs6887695) with psoriasis and psoriatic arthritis. Rheumatol. Int. 33, 1785-1790. doi: 10.1007/s00296-012-2637-4

Zotti, T., Polvere, I., Voccola, S., Vito, P., and Stilo, R. (2018). CARD14/CARMA2 signaling and its role in inflammatory skin disorders. Front. Immunol. 9:2167. doi: 10.3389/fimmu.2018.02167

Zuo, X., Sun, L., Yin, X., Gao, J., Sheng, Y., Xu, J., et al. (2015). Whole-exome SNP array identifies 15 new susceptibility loci for psoriasis. Nat. Commun. 6:6793. doi: $10.1038 /$ ncomms 7793

Conflict of Interest Statement: The authors declare that the research was conducted in the absence of any commercial or financial relationships that could be construed as a potential conflict of interest.

Copyright (c) 2019 Gunter, Yap, Chua and Yap. This is an open-access article distributed under the terms of the Creative Commons Attribution License (CC BY). The use, distribution or reproduction in other forums is permitted, provided the original author(s) and the copyright owner(s) are credited and that the original publication in this journal is cited, in accordance with accepted academic practice. No use, distribution or reproduction is permitted which does not comply with these terms. 